\title{
A Conceptual Model and Measurement of Identity-Based, Existential Annihilation Anxieties (EAA)
}

\author{
Ibrahim A. Kira ${ }^{1,2^{*}}$, Thomas Templin ${ }^{3}$, Linda Lewandowski ${ }^{4}$, Hanaa Shuwiekh ${ }^{5}$ \\ ${ }^{1}$ Center for Cumulative Trauma Studies, Stone Mountain, GA, USA \\ ${ }^{2}$ Center for the Study of Stress, Trauma, and Resilience, Georgia State University, Atlanta, GA, USA \\ ${ }^{3}$ Wayne State University, Detroit, MI, USA \\ ${ }^{4}$ The University of Toledo, Toledo, OH, USA \\ ${ }^{5}$ Fayoum University, Fayoum, Egypt \\ Email: *kiraaref@aol.com
}

How to cite this paper: Kira, I. A., Templin, T., Lewandowski, L., \& Shuwiekh, H. (2018). A Conceptual Model and Measurement of Identity-Based, Existential Annihilation Anxieties (EAA). Psychology, 9, 1306-1328.

https://doi.org/10.4236/psych.2018.96080

Received: May 14, 2018

Accepted: June 25, 2018

Published: June 28, 2018

Copyright $\odot 2018$ by authors and Scientific Research Publishing Inc. This work is licensed under the Creative Commons Attribution International License (CC BY 4.0).

http://creativecommons.org/licenses/by/4.0/

\begin{abstract}
Existential (annihilation) anxiety (EAA) and its significant role in PTSD, complex PTSD and mental and physical health, were a long ignored variable in the mainstream clinical science. Further collective EAA is one of the important dimensions missing in the theory and measurement of EAA. The study evaluated the psychometric properties of an existing measure of existential annihilation scale (EAA) (Kira et al., 2012b), that had previously developed based on an integrative framework of identity-based existential annihilation anxiety (EAA) that include most of the personal and collective dimensions of EAA. We reanalyzed the data in seven studies that utilized the measure, conducting exploratory and confirmatory factor analysis for the pooled data $(\mathrm{N}=2436)$, as well as path analysis with EAA as a mediator of the effects of cumulative stress and trauma on PTSD. We conducted Multigroup invariance to test the invariance of the measurement model as well as the predictive structural model across groups. The short measure found to have good internal consistency and test-retest stability, as well as construct, convergent, divergent and predictive validity and is strongly invariant across the main groups. As hypothesized, by the integrated model of EAA, EAA fully mediated the effects of cumulative trauma on PTSD. The results confirm at least in part the validity and utility of the integrative conceptual framework. Further development of the measurement model in future studies was proposed to include fear of death that was not included in the evaluated measure and is one of the components of integrated framework of EAA. The importance of integrating EAA in the mainstream clinical science and intervention was discussed.
\end{abstract}




\section{Keywords}

Existential Annihilation Anxiety, Collective Terror Management, Extinction Salience, Multigroup Invariance, Psychometric Properties, Identity

\section{Introduction}

Existential (annihilation) anxiety (EAA) and its significant role in PTSD, complex PTSD and mental and physical health, were a long ignored variable in the mainstream clinical science. Integrating its conceptual models in studying PTSD, complex PTSD and post-cumulative stress and trauma disorders was mostly resisted. Developing an integrated conceptual framework of EAA and publishing and disseminating solid empirical research was resisted by most peer-reviewed journals from both traditionally dominant sides: the psychoanalytical and the cognitive-behavioral focused journals. The focus in clinical psychology and related disciplines was more on general anxiety. Specific existential anxieties intensified by threats to the existence of one or more of the person's multiple identities represent the most severe anxieties. Specific anxieties about such threats are mostly under-studied in clinical, social and political psychology. Further, existing studies of different existential anxieties are fragmented and do not present a coherent framework. Innovative conceptual and empirical integration that combine and refine the different models of existential anxieties is important to improve our understanding of its dynamics and its effects on mental and physical health. In current article, we will conceptually and empirically integrate different kinds of existential anxieties, annihilation anxieties, and death anxieties frameworks and propose a measurement strategy to test the validity and utility of the integrated conceptual model.

Existential anxieties (EA) (anxieties caused by events that threatened the existence of one of the person's identities) (e.g., Berman, Weems, \& Stickle, 2006; Shaver, \& Mikulincer, 2012; Weems, Costa, Dehon, \& Berman, 2004), annihilation anxieties (AA) (fear of being overwhelmed, merged, penetrated, fragmented, and destroyed, that is triggered by survival threats) (e.g., Hurvich, 2004; Allen, Hurvich, \& Mcguire, 2017), and death anxiety (anxiety caused by the anticipation of death) (e.g., Iverach, Menzies, \& Menzies, 2014) and mortality salience (the inevitability of dying) (e.g., Burke, Martens, \& Faucher, 2010) are unique but overlapping conceptual frameworks. They are all related to severe threats to some of the person's different identities with different intensities of related anxieties. Existential Annihilation anxieties (EAA) can be a unifying and integrative concept that includes anxieties that may erupt upon exposure to person's different personal, role, physical and social identities. EAAs, in the proposed framework, significantly contribute to mediating the effects of cumulative trauma on PTSD and mental health.

Annihilation anxiety (AA) proposed in psychoanalytic literature is a very 
broad concept, but unfortunately has been seen through a very narrow lens, i.e., the psychic anxieties about the mere existence of the person's psychic (i.e., personal) identity, ignoring the existential threats to the person's social and physical identities. Annihilation Anxiety indeed is a constant confrontation with dangers to psychic survival. Death anxiety, on the other hand, is the anxieties about the inevitable physical death of the individual or current threats of physical elimination. Psychic anxieties and fear of death are focused on different anxieties about the existence of different identities of the individual. Further, these two frameworks have an individualistic bias. The social dimensions of the individual's, which is one of his /her core existence, are ignored in these frameworks. Collective AA anxieties (anxiety caused by events that threaten one of the person's groups of belonging, or his collective identities) may be triggered by events that threaten the individual's group existence. Examples are the Holocaust and other genocides, and similar events set off by the dynamics of inter-group conflicts. Further, fear of the extinction (or the demise) of a group, a nation, a civilization or the species, implied in the atomic age, globalization and climate change and the potential end of life can be another dimension related to EAA (Kira, 2002). End of life was predicted and part of core beliefs in most religious traditions.

Additionally, threats to social identity status in severe discriminations, intense power, and status struggle (e.g., caste system, slavery), and unemployment are not directly included in any of current popular frameworks. The loss of self-perceived social status but not the loss of income or social support explained a significant variance for the adverse health effects of unemployment (Krug, \& Eberl, 2018). While anxieties about existence can vary in their intensities, existential annihilation anxieties (EAA) represent the severe endpoints in the continuum of such anxieties.

There is a lack of a conceptual integrative model of EAA and comprehensive parsimonious tools for its measurement that are based on robust, comprehensive theoretical grounding.

\section{Identity-Based EAA Conceptual Framework}

The proposed conceptual framework is based on the developmentally-based trauma framework (DBTF) (Kira, 2001; Kira et al., 2013b; Kira et al., 2010; Kira et al., 2015; Kira, Lewandowski, Chiodo, \& Ibrahim, 2014; Kira, et al., 2018a), and collective terror management theory (CTMT) (Kira, 2002). According to DBTF and CTMT, EAA may develop in the individual starting with the individuation processes in early adolescence through adulthood. Identity development through individuation processes marks the emergence and development of agency and interdependence leading to establishing a hierarchy of different intersecting and interacting identities. Some of these identities are more salient or more dormant according to the triggering events and situations. Identity development is related to self-awareness and core beliefs about self, belongings, and meaning in life. Identity hierarchy, as discussed earlier, includes personal, col- 
lective or social, role/status and physical identities. Concerns about the existence, maintenance and continuous emergence of individual's identities can escalate upon exposure to relevant and important threats, stressors, and traumas (e.g., Kira, 2006; Kira, Alawneh, Aboumediane, Mohanesh, Ozkan, \& Alamia, 2011; Kira, Shuwiekh, Al Ibraheem, \& Aljakoub, 2018b; Kira, Shuwiekh, Kucharska, Abu-Ras, \& Bujold-Bugeaud, 2017; Kira, Shuwiekh, Rice, Al Ibraheem, \& Aljakoub, 2017). Such exposure can trigger existential fears of the annihilation of one or all of her/his identities. Psychic EAA emerges when personal identity (i.e., autonomy, agency) is threatened by impending traumatic events such as sexual abuse or rape. Collective EAAs emerges when one of the important groups that the person closely identifies with is threatened, demeaned, or assigned comparative inferior status by other strong competitor or dominant groups (e.g., Kira, Shuwiekh, \& Bujold-Bugeaud, 2015; Kira et al., 2010; Kira, Shuwiekh, \& Bujold-Bugeaud, 2017). EAAs may emerge upon events or chronic conditions that seriously threaten a core achievement/self-actualizing goal or socio-economic status of the individual. Examples are extreme inequalities, poverty, and cast systems, as well as a failing business or education that threatens the individual's socio-economic status and self-evaluations. The fourth major source for EAAs is events that threaten physical survival, i.e., death. Collective identity or type III traumas, such as different discriminations and extreme inequality were found to be the worse trauma type that can impede post-traumatic growth (Kira et al., 2013a). To recap, according to the DBTF and CTMT, there are four major sources of EAA (Kira et al., 2012a): the threats to personal identity's psychic annihilation, the threats to collective and social identities, the threats to identity status by social structure traumas (social-structural violence), and the threat to the physical identity of the individual. These four types of threats, when concurrently exist can intersect in amplifications loop.

The threats to the physical identity are the main focus of current psychiatric trauma and terror management theories. Mortality salience, death threat and the resulted fear of physical annihilation (i.e., death) is the focus of terror management theory. Fear of personal identity psychic annihilation is the focus of annihilation anxiety theory in psychoanalytic literature. However, fear and anxieties around collective annihilation of one or more of the person's social identities or social identity status, and extinction salience is almost missing variables in the mainstream psychology. As noticed, the current mainstream psychology, has an individualistic bias (e.g., Christopher \& Hickinbottom, 2008), ignoring an important part of the personal existence, which make it deficient and unable to predict or develop strategies to prevent group-based violence. Group-based violence is one of the current challenges to our discipline. Yet, political psychology recognizes the importance of the concept of collective annihilation anxieties in the Holocaust and genocides studies (e.g., Hirschberger, Ein-Dor, Leidner, \& Saguy, 2016; Kira, Alawneh, Aboumediene, Lewandowski, \& Laddis, 2014; Shrira, 2015; Yair, 2014; Wohl, Branscombe, \& Reysen, 2010).

Fear of physical death is related to the salience of mortality for individuals, 
while fear of group existential annihilation is more related to the extinction salience of the groups, cultures, and civilizations, and potentially species (Kira, 2002). Death or mortality salience and related terror management strategies (e.g., Pyszczynski, Greenberg, \& Solomon, 1999) may be different from or intersect and interact with collective terror management strategies (CTM) related to identities' extinction salience. Core strategies that may buffer or alleviate CTM related anxieties include, strong will to exist, live and survive, religiosity, and spirituality, which help the individual to potentially recover from the terror related to the inevitability of extinction (e.g., group annihilation), and to threats to group identity and recover his/her positive self-evaluation (self-esteem) and perceived social status.

One of the goals of this paper is to further develop a measurement model of EAA that covers its different dimensions. We will evaluate the psychometric properties of one measure of EAA that initially reflected some dimensions of this framework, and use the results to test the framework basic assumptions and to explore further the development of a comprehensive measurement model for EAA.

\section{Measuring EAA}

Hurvich Experience Inventory (HEI), and its different versions (Allen, Hurvich, \& Mcguire, 2017) is a self-report protocol that associate with projective measures of annihilation anxiety (Hurvich, Benveniste, Howard, \& Coonerty, 1993), try to measure the psychoanalytic concept of personal identity-related annihilation anxiety. They are many measures of existential anxiety (EA) with most of them is focused on fear of death (e.g. van Bruggen, Vos, Westerhof, Bohlmeijer, \& Glas, 2015). A recent attempt to introduce and measure EAA, from an integrative theoretical framework that includes especially group-based existential AA and social status related AA, in addition to the psychic annihilation fears is proposed by Kira and Colleagues (Kira et al. 2012b; Kira, Shuwiekh, Rice, Al Ibraheem, \& Aljakoub, 2017). The developed short measure has good reliability, strong divergent and predictive validity and fits the theoretical assumptions that underlie the construct. The measure is not intended to be a diagnostic tool and can be useful in clinical screening, advanced case conceptualization, and in psychological and political research, especially with the multiply traumatized. Several subsequent studies using the measure help provide an accurate picture of its psychometric properties.

One of the goals of this paper is to evaluate and further develop the AA short measure based on the published studies and collected data and a more developed conceptual framework. The study hypothesized that the short measure will have good reliability, stability, convergent, divergent and predicative validity. According to the proposed theory, we further hypothesized that EAA will significantly mediate the effects of cumulative trauma on PTSD. While the EAA conceptually is multidimensional, we expect that a one first or second order unitary factor will emerge as the theory proposed the intersection of all types of EAA that belong to the same person. 


\section{Methods}

\subsection{Procedures}

There are three adult samples and four adolescent samples that utilized this short three items measure. In the current study, we combined the seven samples in one dataset $(\mathrm{N}=2436)$.

The scale developers assumed that there are at least three primary sources of the emergence of annihilation threats. They include threats to personal identity, collective identity, and threats from severe societal structural inequalities. Three items, each represents one of the three components was used, e.g., "Because of what has happened to me personally or is happening to me personally, I sometimes worry that I just lose my sense of self (I worry that I will cease to exist as a person)." The answer was structured on a 5-point Likert-scale (5 = strongly agree; 4 = agree; 3 = not sure; 2 = disagree; 1 = strongly disagree). A score of 3 or higher on any item indicates the presence of at least one related concern.

Researchers used the 3-item scale previously for Iraqi refugees in Michigan, on three samples of Palestinian adults and adolescents and of mental health clients $(\mathrm{N}=399)$. In the initial validation study and subsequent studies, its alpha reliability ranged from $.90-.95$, and its convergent, discriminant and predictive validity were adequate (Kira, et al., 2012b). In the validation study, using multiple regression, although all trauma types predicted AA, collective identity trauma was the highest predictor $(\beta=.74, p<.001)$. Negative appraisal of different survival and identity traumas was a stronger predictor of AA than just the occurrence of trauma. AA was found to be a significant predictor of PTSD $(\beta=.46, p<.001)$, cumulative trauma disorder (CTD; $\beta=.43, p<.001)$, general anxiety $(\beta=.40, p<.001)$, depression $(\beta=.38, p<.001)$, and poor self-rated health $\left(\beta=.14,{ }^{\star} p<.01\right)$. Annihilation anxiety mediated the effects of cumulative negative appraisal on mental and physical health. AA highly associated with the CTD-Dissociation/Psychosis Sub-scale. The research found similar results in subsequent studies on Palestinians (Kira, Alawneh, Aboumediene, Lewandowski, \& Laddis, 2014), and Syrians refugees (Kira, Shuwiekh, Rice, Ibraheem, \& Aljakoub, 2017).

\subsection{Participants}

Description of the studies that used the EAA measure included in the combined sample:

\subsubsection{Adult Samples}

Mental health clinic patients in the USA $(N=399)$ : Participants included 399 adults' mental health clients in the USA. For demographics of the sample and other statistics see Kira, Fawzi, \& Fawzi, 2013.

Palestinians in Gaza sample $(N=132)$ : Participants included 132 adults who live in Gaza, Palestinian territories. For demographics of the sample and other statistics see (Kira, Omidy, \& Ashby, 2014).

Egyptian College Students sample $(N=620) 620$ undergraduate students 
enrolled in Cairo University (Cairo, Egypt) and South Valley University (Qena, Egypt). 69\% females, age range from 18 - 22 (for more details see, Shuwiekh, Kira, \& Ashby, 2018).

\subsubsection{Adolescent Samples}

African Americans adolescents $(N=181)$ Participants included in the current analysis were 181 African American adolescents from Grades 5 through 12. The age range was between 11 and 17 years $(M=14.10, S D=1.43)$, with $24.3 \%$ in the 11 to 13 age group and $75.7 \%$ in the 14 to 17 age group. The sample was $40.3 \%$ males and 59.7\% females. For demographics of the sample and other statistics see Kira, Somers, Lewandowski, \& Chiodo, 2012.

Iraqi refugee adolescents $(N=224)$ : Participants' age ranged from 12 - 17 ((M $(S D)=13.49(1.59))$. All participants were students from different schools in Dearborn and Detroit, Michigan, with $46 \%$ belonging to grades $5 \%$ to $7 \%$ and $54 \%$ belonging to the grades 8 th -12 th. Among them, $52.5 \%$ were males and 47\% females, 98.6\% were Muslim Shiites, and the rest were Muslim Sunni (for details see: Kira, Lewandowski, Chiodo, \& Ibrahim, 2014).

Palestinians adolescents in West Bank $(N=438)$ : Participants were 438 Palestinian adolescents from the West Bank, age ranged from 12 to 19 with a mean of 15.66 and SD of $1.43 \%, 54.6 \%$ males $(\mathrm{N}=239), 39.9 \%$ were attending middle school $(\mathrm{N}=175)$ and $60.1 \%$ were attending high school $(\mathrm{N}=263)$. For place of residence, $52.3 \%$ resided in cities $(\mathrm{N}=229), 44.4 \%$ resided in villages $(\mathrm{N}=195)$, while $3.2 \%$ resided in refugee camps $(\mathrm{N}=14)$. For details see, Kira et al., 2013b.

Palestinians adolescents in Gaza $(N=442)$ : Gaza's Participants included 442 adolescents, $47.5 \%$ males, and $52.5 \%$ females. They included $5 \%$ from villages "residents, 50.3\% from Gaza city residents, and $44.7 \%$ from refugee camps" residents. Age ranged between 11 and 19, with a mean of 15.89 and SD of 2.86. Family size average was 9.77 with SD of 2.79. For detail see Kira et al., 2011.

\subsection{Statistical Analyses}

The data were analyzed utilizing IBM-SPSS 22 and Amos 22 software. Comparing Cohen (1992) sample size recommendations to achieve medium population effect size at power $=.80$ for $\alpha=.05$ for the number of variables, the sample size of each group was adequate and the combined sample $(\mathrm{N}=2436)$ far exceeded the recommended sample size to achieve a high effect size considering the number of the dependent variables in the correlation matrix. We conducted zero-order correlation between EAA and the other relevant variables in each of the studies to check the consistency of its divergent and predictive validity indicators across studies. To determine the EAA's structural validity and its factor structure scores, we split the combined sample of the seven studies $(\mathrm{N}=2432)$ into two subsamples $(\mathrm{N}=1218$ each) using SPSS commands (e.g., select a random sample of the cases). We conducted exploratory (on the first sub-sample) and confirmatory factor analysis (on the second subsample). We conducted confirmatory factor analysis on the scale as a unitary factor. Following Byrne's (2012) recom- 
mendations, the measurement model was evaluated to ensure an acceptable fit with the sample data. The criteria for good model fit were a non-significant chi-square $\left(\chi^{2}\right)$, chi-square/degrees of freedom ( $\chi^{2} /$ d.f. $\left.>5\right)$, comparative fit index (CFI) values $>0.90$, and root-mean-square error of approximation (RMSEA) values $<0.06$ (Weston \& Gore, 2006). We investigated the reliability of the scale with the Cronbach's alpha technique and its stability by the test-retest procedure. To test its predictive validity, we conducted path analysis between the independent and dependent variables. We used a bootstrap procedure with 10,000 bootstrap samples to examine the significance of direct, indirect and total effects and $95 \%$ bias-corrected confidence intervals.

To assess whether the EAA scale is invariant across different samples and genders, we conducted multi-group invariance analysis. Further, we conducted similar analysis to determine if the predictive model of EAA in invariant across groups. Although there is broad acceptance of the steps for testing measurement invariance, the criteria for evaluating the fit of the models at each level are not as clear (see, e.g., Meade, Johnson, \& Braddy, 2008). The statisticians propose guidelines for evaluating model fit, but there are no widely agreed on absolute criteria for determining whether the constraints in a model lead to an unacceptable level of the misfit. When evaluating models, we focus on the (RMSEA), the (CFI), and the Tucker-Lewis index (TLI). We used the guidelines that well-fitting models will have RMSEAs at or below 0.08. If adding invariance constraints in a model (a more restrictive model) lead to a substantial decline in fit indices in comparison with a less restrictive model, the invariance constraints are not supported. If imposing invariance constraints in a model (a more restrictive model) does not lead to a substantial decrement in fit indices in comparison with the less restrictive model, the strict invariance is accepted. The null hypothesis of invariance should not be rejected when changes in CFI are less than or equal to .01, and if RMSEA is less than or equal to .015 (Chen, 2007).

Four invariance nested models were tested sequentially: a configural invariance model, a metric invariance model, a scalar invariance model, and a strict invariance model. In the configural model, (i.e., equal form), the parameters are all freely estimated across groups. In the metric model (i.e. weak or partial invariance), the parameters are constrained to be identical across groups. In the scalar model or "strong invariance", variables and paths variances are set to be equal across groups. Lastly, the strict model "strict invariance" additionally constrains the residuals to be the same across the samples.

\section{Results}

\subsection{Descriptive Differences between Groups in EAA}

Using ANOVA with multiple comparisons, there were no significant differences between the scores on EAA between the seven groups except for the differences between African American and Iraq refugee adolescents. Adults in Gaza scored the highest followed by mental health clinic patients in all of the three types of 
EAA (personal identity (psychic) EAA, collective identity EAA, and status identity EAA) and of the total score. Gaza adults and mental health clinic patients scored the highest on all the measured types of EAA and the differences were highly significant, which further give an indication for its discriminant validity and its ability to identify the most traumatized and the clinical populations. Figures 1-4 present the plots of means of each of the EAA type and for the total score for the seven samples. Table 1 provides the means, standard deviations

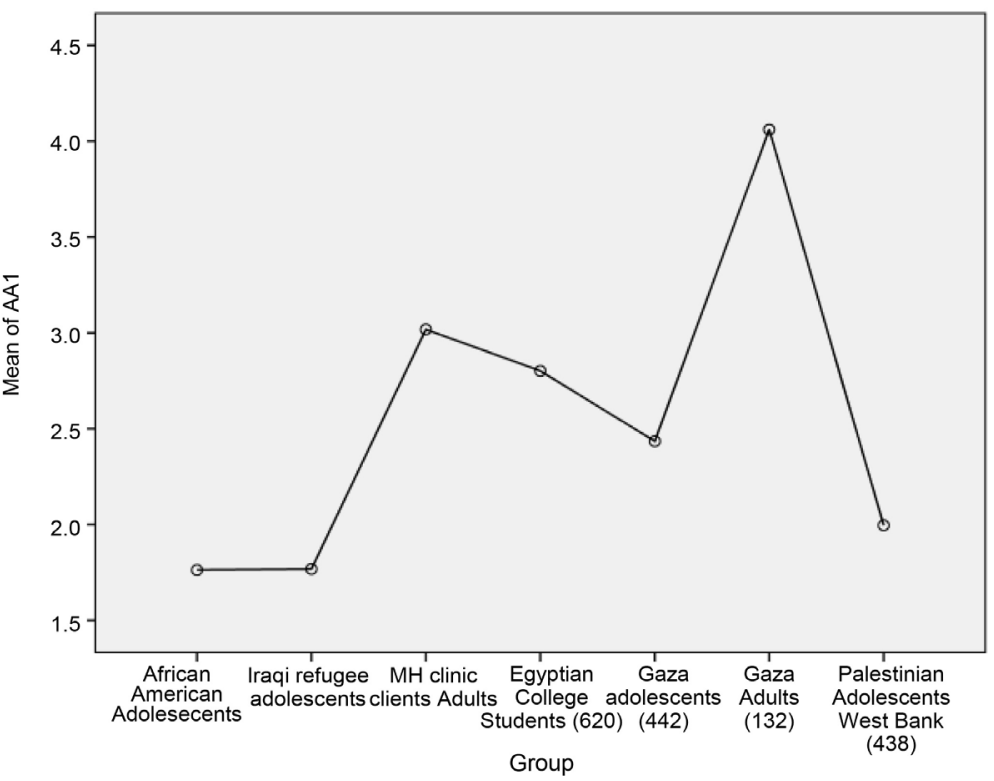

Figure 1. Means plot for the personal Identity (psychic) existential annihilation anxiety in the seven samples.

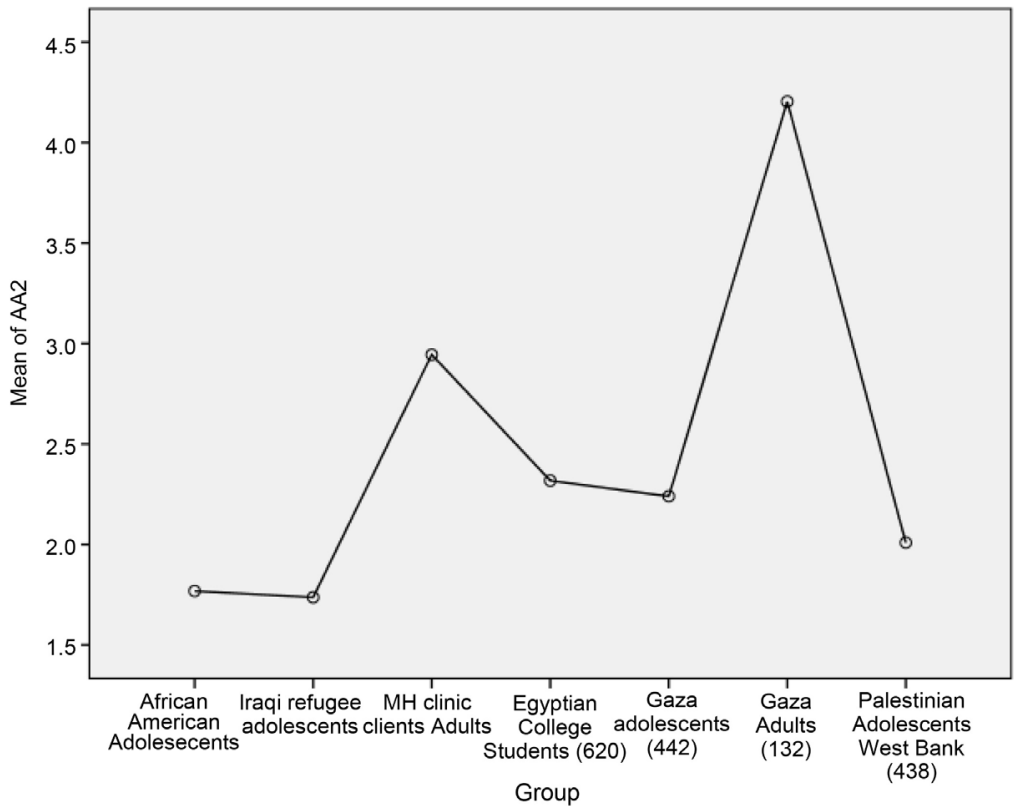

Figure 2. Means plot for the collective identity existential annihilation anxiety in the seven samples. 


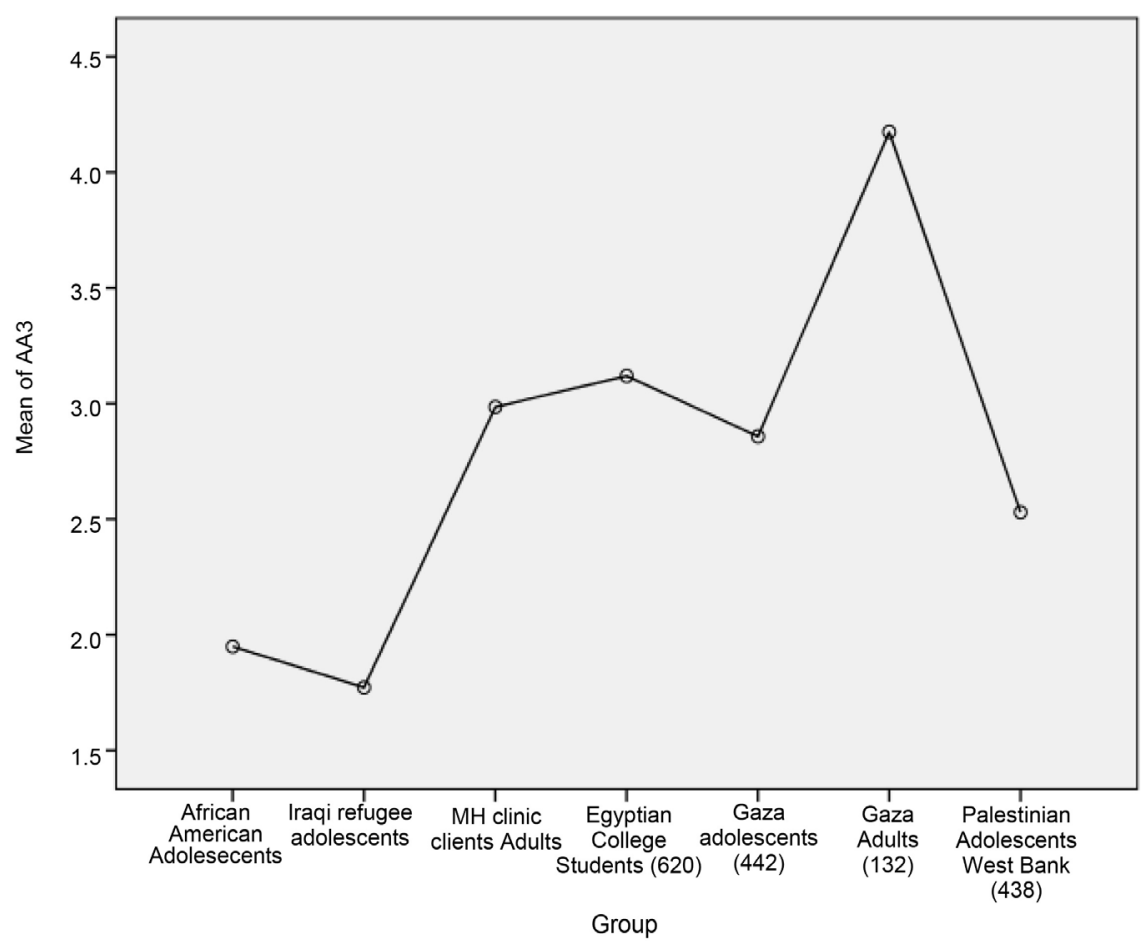

Figure 3. Means plot for the status identity existential annihilation anxiety in the seven samples.

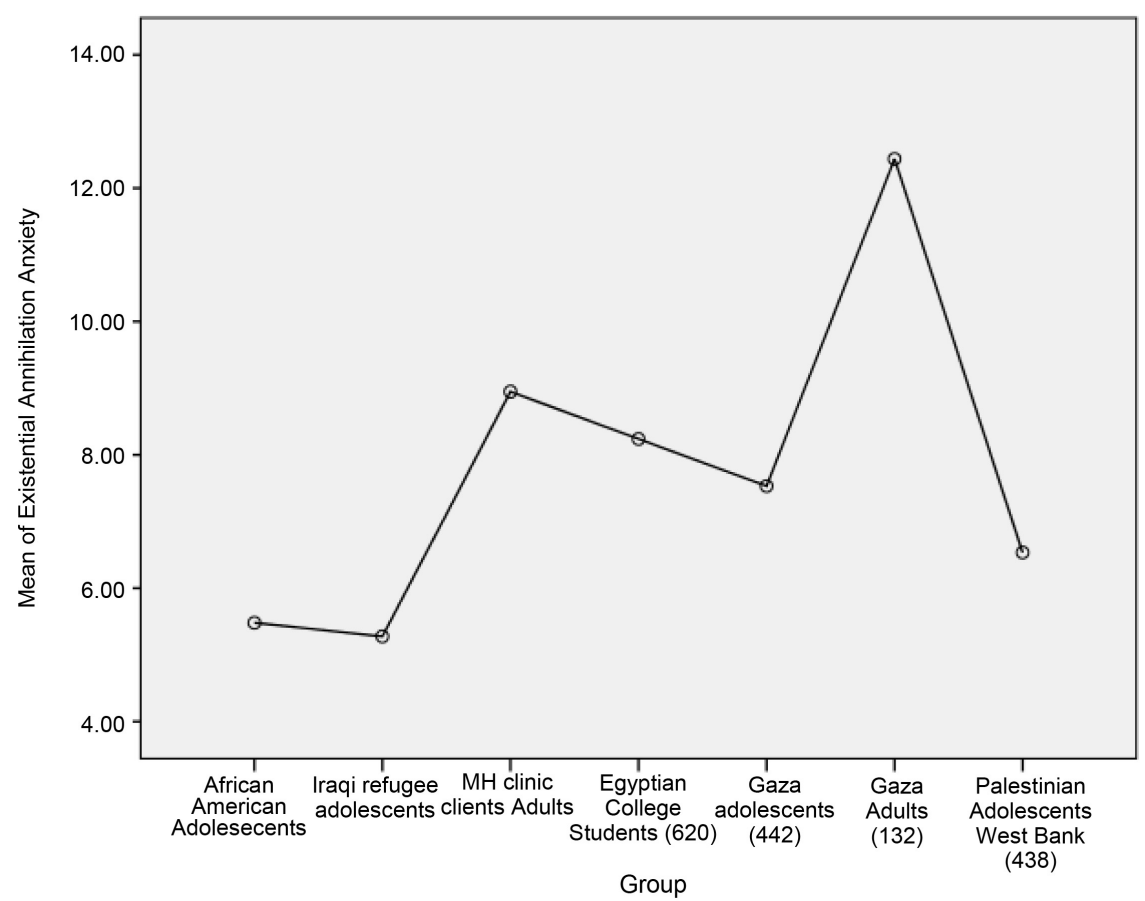

Figure 4. Means plot for the total identity existential annihilation anxiety in the seven samples.

and standard errors and lower and upper bound of $95 \%$ confidence interval of the mean score of EAA total score in each sample. 
Table 1. Means, standard deviations, standard errors and lower and upper bound of $95 \%$ confidence interval of the mean score of EAA in each sample.

\begin{tabular}{|c|c|c|c|c|c|}
\hline & \multirow{3}{*}{ Mean } & \multirow{3}{*}{$\begin{array}{l}\text { Standard } \\
\text { Deviation }\end{array}$} & \multirow{3}{*}{$\begin{array}{l}\text { Standard } \\
\text { Error }\end{array}$} & \multicolumn{2}{|c|}{$\begin{array}{l}\text { 95\% Confidence Interval } \\
\text { for Mean }\end{array}$} \\
\hline & & & & Lower & Upper \\
\hline & & & & Bound & Bound \\
\hline African American Adolescents & 5.48 & 2.19 & .16 & 5.16 & 5.81 \\
\hline Iraqi refugee adolescents & 5.28 & 3.50 & .23 & 4.82 & 5.74 \\
\hline Mental health clinic clients Adults & 8.95 & 3.82 & .19 & 8.57 & 9.32 \\
\hline Egyptian College students & 8.24 & 2.85 & .11 & 8.01 & 8.46 \\
\hline Gaza adolescents & 7.53 & 3.27 & .16 & 7.23 & 7.84 \\
\hline Gaza Adults & 12.44 & 4.75 & .41 & 11.62 & 13.26 \\
\hline Palestinian Adolescents West Bank & 6.54 & 3.23 & .15 & 6.23 & 6.84 \\
\hline Total & 7.67 & 3.70 & .08 & 7.53 & 7.82 \\
\hline
\end{tabular}

\subsection{Correlational Results}

EAA significantly correlated with PTSD and all its four subscales. It associated with depression, poor health, with cumulative trauma, with identity salience, with identity traumas (collective and personal), with birthing trauma and gender discrimination, as well as survival and to some extent secondary traumas. It associated with poverty. It associated with fear of death. It was associated with the internalized stigma of mental illness in the mental health clinic sample. It was associated with negative appraisal of stressful and traumatic events. All these associations lent support to the EAA conceptual, construct, convergent and predictive validity. It was associated negatively with stress-related growth, futuristic orientation, and optimism, which lend support to its divergent validity. Table 2 summarizes these correlations.

\subsection{Reliability and Stability}

Alpha reliability ranged in the seven data sets between .70 and .93 , with the highest in the clinic sample (.93). The reliability of the pooled data $(\mathrm{N}=2743)$ was .80 . Test-retest reliability in a small sample of 35 and the 6-week interval was .94 .

Factor Analysis. Exploratory and Confirmatory and the invariance of the measurement model.

Using the first split sample of adults and adolescent $(\mathrm{N}=1216)$, we conducted Principal.

Component Factor Analysis of the scale. The analysis yielded one factor accounted for $72.16 \%$ of the variance. Table 3 includes commonalities and factor loadings of each item.

Using the second split sample $(\mathrm{N}=1218)$, we conducted confirmatory factor analysis. The one factor scale had good fit with the data (Chi Square $=.015$, d.f. $=$ $1, p=.903, C F I=1.00, R M S E A=.000)$. Figure 5 provides the results of the confirmatory factor analysis. 
Table 2. Zero-order correlations between EAA and different variables in the seven samples.

\begin{tabular}{|c|c|c|c|c|c|c|c|}
\hline Samples/Variables & $\begin{array}{c}\text { MH } \\
\text { Clinic } \\
\text { Adults }\end{array}$ & $\begin{array}{l}\text { Palestinians } \\
\text { In Gaza } \\
\text { Adults }\end{array}$ & $\begin{array}{l}\text { Egyptian } \\
\text { College } \\
\text { Students }\end{array}$ & $\begin{array}{c}\text { African } \\
\text { American } \\
\text { Adolescents }\end{array}$ & $\begin{array}{l}\text { Iraqi Refugee } \\
\text { Adolescents }\end{array}$ & $\begin{array}{c}\text { Palestinian } \\
\text { Adolescents in } \\
\text { West Bank }\end{array}$ & $\begin{array}{c}\text { Palestinian } \\
\text { Adolescents } \\
\text { In Gaza }\end{array}$ \\
\hline PTSD & $.45^{\star * *}$ & $.56^{* * *}$ & $.36^{* * *}$ & $.24^{* * *}$ & $.19^{* *}$ & $.27^{\star * *}$ & $.33^{* *}$ \\
\hline PTSD-RE & $.47^{\star * *}$ & $.48^{\star * *}$ & $.32^{* * *}$ & $.15^{\star}$ & $18^{* *}$ & $.27^{\star * *}$ & $.28^{\star * *}$ \\
\hline PTSD-AV & $.42^{\star * *}$ & $.37^{\star * *}$ & $.25^{\star * *}$ & $.23^{\star * *}$ & $.17^{\star *}$ & $.24^{\star * *}$ & $.26^{* * *}$ \\
\hline PTSD-AR & $.42^{\star * *}$ & $.38^{\star * *}$ & $.32^{\star * *}$ & $.21^{\star * *}$ & $.08^{+}$ & $.22^{* * *}$ & $.21^{* * *}$ \\
\hline PTSD-D & $.41^{* * *}$ & $.48^{* * *}$ & $.34^{* * *}$ & $.18^{*}$ & $.17^{\star *}$ & $.31^{* * *}$ & $.31^{* * *}$ \\
\hline Poor Health & $.12^{\star}$ & $.28^{\star * *}$ & $.11^{\star *}$ & $.07^{+}$ & $.16^{*}$ & $.13^{* *}$ & $.12^{*}$ \\
\hline Cumulative Trauma & $.34^{* * *}$ & $.19^{*}$ & $.40^{* * *}$ & $.61^{* * *}$ & $.82^{* * *}$ & $.19^{* * *}$ & $.16^{* * *}$ \\
\hline $\begin{array}{c}\text { Collective Identity } \\
\text { Traumas }\end{array}$ & $.93^{* * *}$ & $.21^{*}$ & $.12^{\star * *}$ & $.24^{\star * *}$ & $.24^{* * *}$ & $.37^{* * *}$ & $.12^{*}$ \\
\hline $\begin{array}{c}\text { Personal } \\
\text { identity traumas }\end{array}$ & $.33^{* * *}$ & .03 & $.16^{* * *}$ & $.20^{\star *}$ & $.16^{*}$ & $.13^{* *}$ & $.10^{*}$ \\
\hline Survival traumas & $.25^{\star * *}$ & $.27^{\star * *}$ & $.07^{+}$ & $.09^{+}$ & $.16^{*}$ & $.15^{\star * *}$ & .07 \\
\hline Secondary Traumas & $.49^{* * *}$ & .03 & $.09^{*}$ & $.19^{*}$ & $.29^{* * *}$ & $.17^{* * *}$ & $.10^{*}$ \\
\hline Depression & $.35^{\star * *}$ & $.48^{* * *}$ & $.40^{* * *}$ & NM & NM & $.31^{* * *}$ & NM \\
\hline ISMI & $.37^{\star * *}$ & NM & NM & NM & NM & NM & NM \\
\hline Gender Discrimination & NM & $.24^{* *}$ & $.15^{* * *}$ & NM & NM & NM & NM \\
\hline Poverty & $.27^{\star * *}$ & .NM & $.09^{+}$ & $.29^{\star *}$ & $.50^{* * *}$ & $.29^{* * *}$ & $.52^{\star * *}$ \\
\hline $\begin{array}{l}\text { Negative Appraisal of } \\
\text { traumatic events }\end{array}$ & $.50^{* * *}$ & $.18^{*}$ & $.28^{* * *}$ & .06 & $.11^{+}$ & $.16^{* * *}$ & $.11^{*}$ \\
\hline Identity Salience & NM & $.55^{\star * \star}$ & NM & NM & NM & $.17^{\star * *}$ & $.27^{\star * *}$ \\
\hline Fear of Death & NM & $.47^{* * *}$ & NM & NM & NM & $.20^{* * *}$ & $.19^{* * *}$ \\
\hline Stress related growth & NM & $-.18^{*}$ & NM & NM & NM & NM & $-.14^{* * *}$ \\
\hline Birthing Trauma & NM & NM & NM & $.16^{*}$ & $.22^{* *}$ & $.12^{\star}$ & $.31^{\star * *}$ \\
\hline Futuristic Orientation & NM & $-.23^{\star \star}$ & NM & NM & NM & $-.22^{\star * \star}$ & -.06 \\
\hline Optimism & NM & $-.25^{\star *}$ & NM & NM & NM & $-.15^{\star * *}$ & $-.10^{*}$ \\
\hline
\end{tabular}

Note: ${ }^{+} p<.10 .{ }^{*} p<.05 .{ }^{* *} p<.01 .{ }^{* *} p<.001$.; Note. $N M=$ Not measured in this data set. Note: $P T S D=$ Posttraumatic stress disorder, PTSD-RE $=P T S D$ re-experiencing, $P T S D-A V=P T S D$ avoidance, $P T S D-A R=P T S D$-arousal, $P T S D-D=P T S D$-dissociation, ISMI + internalized stigma of mental illness.

Table 3. Mean, standard deviation, communalities and factor Loadings of each item of EAA.

\begin{tabular}{lccccc}
\hline Items & Mean & SD & Commonalities & Loadings \\
\hline 1) Because of what happened to me, I sometimes worry that I just lose my sense of self & 2.52 & 1.42 & .713 & .845 \\
2) sometimes I feel the threat of extermination of my group because of discrimination & 2.36 & 1.41 & .753 & .868 \\
3) I feel threatened by extreme inequalities in this society & 2.79 & 1.52 & .698 & .836 \\
\hline
\end{tabular}

Further, a multigroup analysis was conducted to examine the measurement invariance of the scale across genders. We tested for configural invariance (same variables and paths for each variable across the two samples). Results showed an acceptable model fit, (Chi-square $=2.655, d f=2$, Chi-squarel $d f=1.327$, $p>.265, R M S E A=.000, C F I=1.000$, and $I F I=1.000, T L I=.999)$. The second 


$$
\begin{gathered}
N=1371 \\
\text { Chi Square }=.015, \text { d.f. }=1, p=.903 \\
C F I=1.000 \\
\text { RMSEA }=.000
\end{gathered}
$$

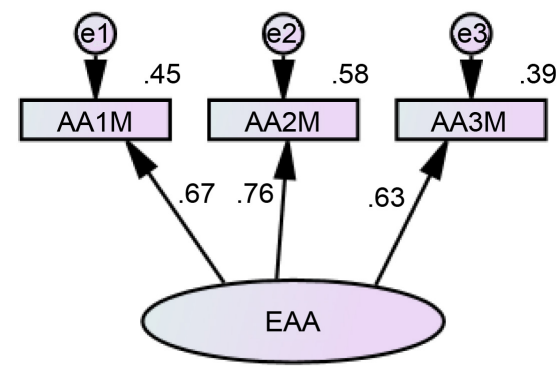

Figure 5. Confirmatory factor analysis of EAA scale for all groups.

model (metric or weak invariance) model holding all variables and paths values invariant across groups showed good fit as well, with no significant reduction in the model fit, (Chi-square $=3.332, d f=3$, Chi-squarel $d f>5, p=0.343, R M S E A=$ $0.007, C F I=1.000, I F I=1.000$, and $T L I=1.000$ ), which means that the model is invariant at this level of analysis. The third model (strong invariance or scalar invariance model in which intercepts additionally restrained), and the fourth model (strict invariance model in which residuals additionally restrained), the fit indicators, showed a similar acceptable range of invariance. These results indicate that the scale is strictly invariant across genders. Table 4 presents the results.

\subsection{The Predictive Validity of the EAA and Its Invariance}

We conducted path analysis, on the combined data, in which of EAA mediated the effects of cumulative trauma on PTSD' four major components (re-experiencing, arousal, avoidance, and dissociation), with PTSD as a latent variable. The model fits well (Chi Square $=9.452$, d.f. $=7, p=.222, C F I=.000$, RMSEA = .012). In this model, EAA fully mediates the effects of cumulative stress and trauma on all PTSD four components. Figure 6 presents the path models that map the direct effects and Table 5 presents the direct, indirect and total effects and their $95 \%$ confidence intervals for the variables in the model.

Further, we conducted a series of Multigroup structural invariance analyses to test the invariance of the predictive path model across genders, across different adult groups and different adolescents groups and across age groups (adults vs. adolescents). For its invariance across genders, we tested for configural invariance. Results showed an acceptable model fit, (Chi-square $=16.743, d f=14$, $p>.270, R M S E A=.009, C F I=.000$, and $I F I=.000, T L I=.999)$. The second model (metric or weak invariance) model holding all variables and paths values invariant across groups showed good fit as well, (Chi-square $=33.785, d f=17$, Chi-squarel $d f>5, p=.343, R M S E A=.020, C F I=.998, I F I=.996$, and $T L I=.998)$, which means that the model is variant at this level of analysis. The third model 
Table 4. Invariance fit indicators of the measurement model of existential annihilation anxiety scale between genders.

\begin{tabular}{ccccccccc}
\hline & chi-square & $d f$ & $p$ & chi-square/df & CFI & TLI & RMSEA & IFI \\
\hline Configural (structure) & 2.655 & 2 & .265 & 1.327 & 1.00 & .999 & .012 & 1.00 \\
Metric (weights) & 3.332 & 3 & .343 & 1.111 & 1.00 & 1.000 & .007 & 1.00 \\
Scalar (intercepts) & 12.521 & 6 & .051 & 2.087 & .996 & .996 & .021 & .996 \\
Strict invariance & 32.211 & 10 & .000 & 3.221 & .986 & .992 & .031 & .986 \\
\hline
\end{tabular}

Table 5. The standardized direct, indirect and total effects and their $95 \%$ confidence intervals of cumulative stress and trauma, and EAA on the four PTSD subscales.

\begin{tabular}{|c|c|c|c|c|c|c|}
\hline \multirow{2}{*}{$\begin{array}{c}\text { Causal } \\
\text { Variables }\end{array}$} & \multicolumn{6}{|c|}{ Endogenous Variables } \\
\hline & EAA & PTSD & Arousal & Avoidance & Dissociation & Re-experiencing \\
\hline \multicolumn{7}{|c|}{ Cumulative Trauma } \\
\hline Direct Effects & $\begin{array}{c}.14^{\star *} \\
(.09 / .17)\end{array}$ & 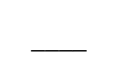 & & - & - & - \\
\hline $\begin{array}{l}\text { Indirect } \\
\text { Effects }\end{array}$ & - & $\begin{array}{c}.06^{* *} \\
(.04 / .08)\end{array}$ & $\begin{array}{c}.05^{\star *} \\
(.03 / .07)\end{array}$ & $\begin{array}{c}.05^{\star *} \\
(.03 / .07)\end{array}$ & $\begin{array}{c}.05^{* *} \\
(.04 / .07)\end{array}$ & $\begin{array}{c}.06^{* *} \\
(.04 / .07)\end{array}$ \\
\hline Total Effects & $\begin{array}{c}.14^{\star *} \\
(.09 / .17)\end{array}$ & $\begin{array}{c}.06^{* *} \\
(.04 / .08)\end{array}$ & $\begin{array}{c}.05^{* *} \\
(.03 / .07)\end{array}$ & $\begin{array}{c}.05^{* *} \\
(.03 / .07)\end{array}$ & $\begin{array}{c}.05^{* *} \\
(.04 / .07)\end{array}$ & $\begin{array}{c}.06^{* *} \\
(.04 / .07)\end{array}$ \\
\hline \multicolumn{7}{|c|}{ Existential Annihilation Anxiety } \\
\hline Direct Effects & & $\begin{array}{c}.46^{* *} \\
(.41 / .50)\end{array}$ & & & $\longrightarrow$ & 工_ \\
\hline $\begin{array}{l}\text { Indirect } \\
\text { Effects }\end{array}$ & & - & $\begin{array}{c}.39^{* *} \\
(.32 / .43)\end{array}$ & $\begin{array}{c}.37^{* *} \\
(.34 / .41)\end{array}$ & $\begin{array}{c}.40^{* *} \\
(.36 / .44)\end{array}$ & $\begin{array}{c}.41^{* *} \\
(.37 / .45)\end{array}$ \\
\hline Total Effects & - & $\begin{array}{c}.46^{* *} \\
(.41 / .50)\end{array}$ & $\begin{array}{c}.39^{* *} \\
(.32 / .43)\end{array}$ & $\begin{array}{c}.37^{\star *} \\
(.34 / .41)\end{array}$ & $\begin{array}{c}.40^{* *} \\
(.36 / .44)\end{array}$ & $\begin{array}{c}.41^{* *} \\
(.37 / .45)\end{array}$ \\
\hline Squared R & .018 & .209 & .707 & .660 & .763 & .804 \\
\hline
\end{tabular}

Note: ${ }^{+} p<.10 .{ }^{*} p<.05 .{ }^{* *} p<.01 .{ }^{* *} p<.001$.

(strong or scalar invariance model in which intercepts additionally restrained), and the fourth model (strict invariance model in which residuals additionally restrained), the fit indicators, showed similar acceptable range. These results indicate that the scale's predictive validity is strictly invariant across genders. Table 5 provides different fit indicators for each model. For the path predictive model invariance across adult groups, we tested for configural invariance. Results showed an acceptable model fit, (Chi-square $=21.571, d f=18$, Chi-squarel $d f=$ $1.198, p .252>5, R M S E A=.013, C F I=.999$, and $I F I=.999, T L I=.997)$. The second model (metric or weak invariance) model holding all variables and paths values invariant across groups showed good fit as well, (Chi-square $=36.004, d f=$ 24, Chi-squarel $d f>5, p=.055, R M S E A=.021, C F I=.996, I F I=.978$, and $T L I=.969)$, which means that the model is invariant at this level of analysis. The third model (strong or scalar invariance model in which intercepts additionally 


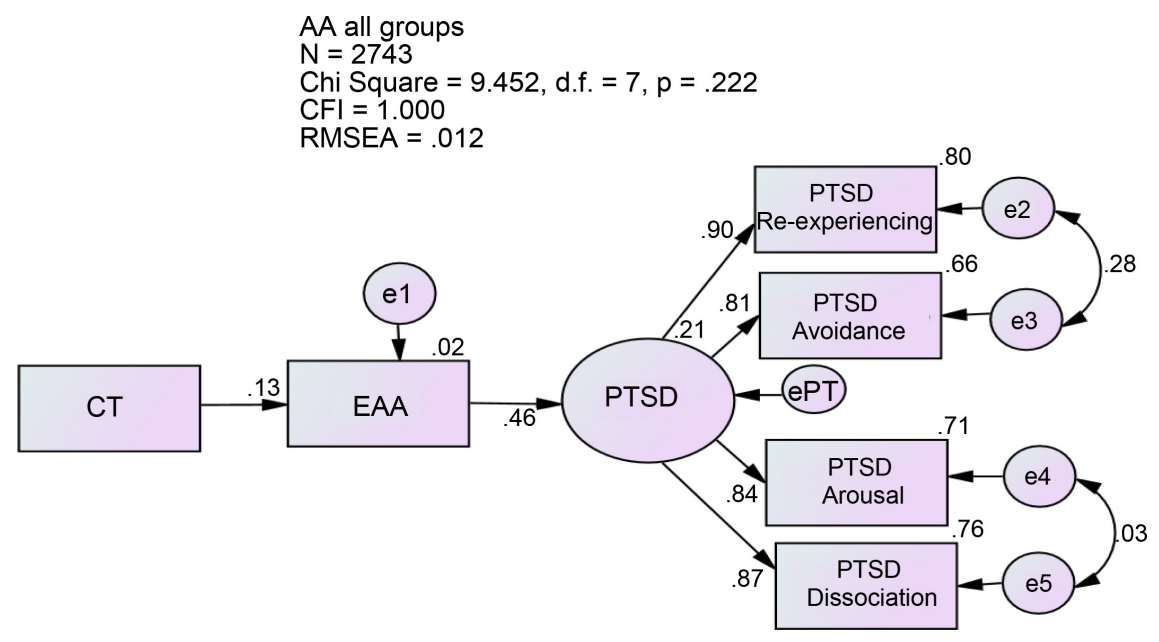

Figure 6. The path model for the standardized direct effects of cumulative stress and trauma on PTSD mediated by EAA.

restrained) was also acceptable. However, for the fourth model (strict invariance model in which residuals additionally restrained), some of the fit indicators, did not show an acceptable range. These results indicate that the scale predictive validity is strongly (not strictly) invariant across different adult groups. Table 5 provides different fit indicators for each model.

For predictive path model invariance across adolescents groups and age groups (adolescents vs. adults), results showed an acceptable model fit for the first three models. For the fourth model (the strict invariance) some of the fit indicators did not show an acceptable range. The results indicate that the scale's predictive validity is strongly (but not strictly) invariant across adolescents groups and age groups. Table 6 provides the fit indicators for each model for these groups.

\section{Conclusions, Discussion, and Proposed Future Development}

Current study tested some assumptions of an integrated model of existential annihilation anxieties using a short parsimonious measure of EAA. The measure that contained three different models of EAA found to be unidimensional which validate the intersectionality hypothesis. Existential anxieties from different sources intersect, feed and amplify each other, as they belong to the same person's existence. EAA found to fully mediate the effects of cumulative trauma on PTSD. This paper charts an alternative trajectory for the integrative study of EAA, asserting that analytic priority rests with understanding identity dynamics and its implications for the integrative theory of EAA. It provided evidence for the clinical importance of all components of EAA, especially those related to the social EAAs that rarely addressed or measured in the literature.

While mortality salience and psychoanalytic psychic AA are important dynamics, extinction salience of the group, can be equally powerful for some individuals and groups and have significant clinical implications. Mortality salience 
Table 6. Invariance fit indicators for the model of the effects of different trauma types mediated by existential annihilation anxiety on PTSD across different groups.

\begin{tabular}{|c|c|c|c|c|c|c|c|c|}
\hline \multicolumn{9}{|c|}{ Invariance Fit Indicators of the Model across Genders } \\
\hline & chi-square & $d f$ & $p$ & chi-square/df & $C F I$ & $T L I$ & RMSEA & $I F I$ \\
\hline Configural (structure) & 16.743 & 14 & .270 & 1.196 & 1.000 & .999 & .009 & 1.000 \\
\hline Metric (weights) & 33.785 & 17 & .009 & 1.987 & .998 & .996 & .020 & .998 \\
\hline Scalar (intercepts) & 45.167 & 21 & .002 & 2.151 & .997 & .996 & .022 & .997 \\
\hline Strict invariance & 238.183 & 28 & .000 & 8.507 & .973 & .971 & .056 & .973 \\
\hline \multicolumn{9}{|c|}{$\begin{array}{l}\text { Invariance Fit Indicators of the Model across the Three Adult Populations: Clinic sample in the } \\
\text { USA, Palestinians Adults in Gaza, and Egyptian College Students }\end{array}$} \\
\hline Configural (structure) & 21.571 & 18 & .252 & 1.198 & .999 & .997 & .013 & .999 \\
\hline Metric (weights) & 36.004 & 24 & .055 & 1.500 & .996 & .993 & .021 & .996 \\
\hline Scalar (intercepts) & 106.955 & 32 & .000 & 3.342 & .978 & .969 & .045 & .978 \\
\hline Strict invariance & 377.001 & 38 & .000 & 9.921 & .900 & .882 & .088 & .900 \\
\hline \multicolumn{9}{|c|}{$\begin{array}{l}\text { Invariance Fit Indicators of the Model across the four adolescent populations: } \\
\text { African Americans, Iraq Refugees Adolescents, Palestinian Adolescents in Gaza, } \\
\text { and Palestinian Adolescents in West Bank }\end{array}$} \\
\hline Configural (structure) & 164.919 & 76 & .000 & 2.170 & .975 & .963 & .030 & .975 \\
\hline Metric (weights) & 272.817 & 91 & .000 & 2.998 & .948 & .936 & .040 & .948 \\
\hline Scalar (intercepts) & 431.128 & 97 & .000 & 4.445 & .904 & .890 & .052 & .905 \\
\hline Strict invariance & 649.800 & 100 & .000 & 6.498 & .843 & .824 & .066 & .843 \\
\hline \multicolumn{9}{|c|}{ Invariance Fit Indicators of the Model across Adults and Adolescents groups } \\
\hline Configural (structure) & 41.931 & 16 & .000 & 2.621 & .995 & .991 & .010 & .995 \\
\hline Metric (weights) & 67.619 & 19 & .000 & 3.559 & .991 & .986 & .011 & .991 \\
\hline Scalar (intercepts) & 116.408 & 23 & .000 & 5.061 & .983 & .978 & .013 & .983 \\
\hline Strict invariance & 363.312 & 35 & .000 & 10.380 & .948 & .948 & .06 & .948 \\
\hline
\end{tabular}

can intersect and interact with the extinction salience within the person's identities hierarchy. In factor analysis, group EAA had the highest commonality and loading on the single factor that found to represent EAA and accounted for $72.16 \%$ of the variance. Further, the different types of EAA found to represent one factor which provided evidence of the validity of the integrative approach of intersecting and interacting identity trauma-based EAA. Future research may plan to establish profiles of EAA in different trauma victims (e.g., torture survivors, veterans, sexual abuse survivors, Holocaust and genocide survivors, minorities, and refugees).

Additionally, the current study established the reliability, stability and predictive validity of EAA measure. EAA short form seems to have good psychometric 
properties with multiply traumatized and clinical populations. Its correlations reflect the good content and conceptual, as well as discriminant and predictive validity. It seems to possess good internal consistency and test-retest stability. It is a parsimonious tool to measure this developed concept. It is easy to use in research projects with multiple traumatized in clinical and non-clinical settings and with adults and adolescents.

In path analysis, EAA fully mediated the effects of cumulative trauma on PTSD, which emphasizes the clinical importance of this long-ignored existential dimension. Recent studies on Syrian refugees in Egypt and the Netherlands and internally displaced replicated these findings and found similar results on the role of EAA in PTSD and other mental health conditions (Al-Ibraheem, Kira, Aljakoub, \& Al-Ibraheem, 2017; Kira, Shuwiekh, Al Ibraheem, \& Aljakoub, 2018b; Kira, Shuwiekh, Rice, Al Ibraheem, \& Aljakoub, 2017). These findings are important to developing more convincing conceptual frameworks and more effective intervention strategies that target EAA in all its components.

However, this short measure though parsimoniously measured most dimensions of the integrated framework; it does not cover all the dimensions discussed in the introduction (does not include enough items that measure role/status identity, and physical identity). To measure this concept in all its dimensions, we developed an expanded version (see Appendix). The measure includes fifteen items that include four subscales: EAA related to personal identity traumas subscale, EAA related to collective identity traumas subscale, EAA related to role/status identity (e.g., relative deprivation and personal achievement and self-actualization) subscale, and EAA related to fear of death. The new scale with its four subscales gives the researcher the option to use one subscale or the other to measure EAA resulted from different threats to different identities, or, alternatively to map the profile of different EAA intensities using the whole scale. Alternatively, the three items short measure discussed here has good psychometrics and is available for research especially with multiply traumatized that may not have the attention span to tolerate longer measures and questionnaires (Allen, Hurvich, \& Mcguire, 2017: p. 7). The EAA scale is not intended for diagnostic purposes, rather for different relevant clinical, social and political research and for advanced clinical case conceptualization. Future studies would be conducted to test this expanded version of EAA with its four subscales.

\section{Acknowledgements}

Authors appreciate the valuable comments provided by Dr. Gilad Hirschberger, School of Psychology, Interdisciplinary Center Herzliya, Herzliya, Israel, on a previous version of the article.

\section{References}

Al-Ibraheem, B., Kira, I., Aljakoub, J., \& Al-Ibraheem, A. (2017). The Health Effect of the Syrian Conflict on IDPs and Refugees. Peace and Conflict: Journal of Peace Psychology, 23, 140-152. https://doi.org/10.1037/pac0000247 
Allen, R., Hurvich, M., \& Mcguire, H. (2017). Diagnostic Utility of the Hurvich Experience Inventory/50. Psychoanalytic Psychology, 34, 271-278. https://doi.org/10.1037/pap0000067

Berman, S. L., Weems, C. F., \& Stickle, T. R. (2006). Existential Anxiety in Adolescents: Prevalence, Structure, Association with Psychological Symptoms and Identity Development. Journal of Youth and Adolescence, 35, 285-292. https://doi.org/10.1007/s10964-006-9032-y

Burke, B. L., Martens, A., \& Faucher, E. H. (2010). Two Decades of Terror Management Theory: A Meta-Analysis of Mortality Salience Research. Personality and Social Psychology Review, 14, 155-195. https://doi.org/10.1177/1088868309352321

Byrne, B. M. (2012). A Primer of LISREL: Basic Applications and Programming for Confirmatory Factor Analytic Models. New York: Springer Science \& Business Media.

Chen, F. F. (2007). Sensitivity of Goodness of Fit Indexes to Lack of Measurement Invariance. Structural Equation Modeling: A Multidisciplinary Journal, 14, 464-504. https://doi.org/10.1080/10705510701301834

Christopher, J. C., \& Hickinbottom, S. (2008). Positive Psychology, Ethnocentrism, and the Disguised Ideology of Individualism. Theory \& Psychology, 18, 563-589. https://doi.org/10.1177/0959354308093396

Cohen, J. (1992). A Power Primer. Psychological Bulletin, 112, 155-159. https://doi.org/10.1037/0033-2909.112.1.155

Hirschberger, G., Ein-Dor, T., Leidner, B., \& Saguy, T. (2016). How Is Existential Threat Related to Intergroup Conflict? Introducing the Multidimensional Existential Threat (MET) Model. Frontiers in Psychology, 7, 1877. https://doi.org/10.3389/fpsyg.2016.01877

Hurvich, M. (2004). Psychic Trauma and Fears of Annihilation. Living with Terror, Working with Trauma: A Clinician's Handbook (pp. 51-66). Latham, MD: Rowman and Littlefield.

Hurvich, M., Benveniste, P., Howard, J., \& Coonerty, S. (1993). Assessment of Annihilation Anxiety from Projective Tests. Perceptual and Motor Skills, 77, 387-401. https://doi.org/10.2466/pms.1993.77.2.387

Iverach, L., Menzies, R. G., \& Menzies, R. E. (2014). Death Anxiety and Its Role in Psychopathology: Reviewing the Status of a Transdiagnostic Construct. Clinical Psychology Review, 34, 580-593. https://doi.org/10.1016/j.cpr.2014.09.002

Kira, I. (2001). Taxonomy of Trauma and Trauma Assessment. Traumatology, 7, 73-86. https://doi.org/10.1177/153476560100700202

Kira, I. (2002). Suicide Terror and Collective Trauma: A Collective Terror Management Paradigm. Paper presented at the American Psychological Association Annual Convention, Chicago, IL, August 2002.

http://psycnet.apa.org/psycextra/316712004-001.pdf\&uid=316712004-001\&db=PE

Kira, I. (2006). Collective Identity Terror in the Israeli-Palestinian Conflict and Potential Solutions. In J. Kuriansky (Ed.), Contemporary Psychology. Terror in the Holy Land: Inside the Anguish of the Israeli-Palestinian Conflict (pp. 125-130). Westport, CT: Praeger Publishers/Greenwood Publishing Group.

Kira, I. A., Lewandowski, L., Chiodo, L., \& Ibrahim, A. (2014). Advances in Systemic Trauma Theory: Traumatogenic Dynamics and Consequences of Backlash as a Multi-Systemic Trauma on Iraqi Refugee Muslim Adolescents. Psychology, 5, 389-412. https://doi.org/10.4236/psych.2014.55050

Kira, I. A., Omidy, A. Z., \& Ashby, J. S. (2014). Cumulative Trauma, Appraisal, and Cop- 
ing in Palestinian and American Indian Adults: Two Cross-Cultural Studies. Traumatology: An International Journal, 20, 119-133. https://doi.org/10.1037/h0099397

Kira, I. A., Shuwiekh, H., Kucharska, J., Fawzi, M., Ashby, J. S., Omidy, A. Z., Abou-Mediene, S., \& Lewandowski, L. (2018a). Trauma Proliferation and Stress Generation (TPSG) Dynamics and Their Implications for Clinical Science. American Journal of Orthopsychiatry. https://doi.org/10.1037/ort0000304

Kira, I. A., Somers, C., Lewandowski, L., \& Chiodo, L. (2012). Attachment Disruptions, IQ, and PTSD in African American Adolescents: A Traumatology Perspective. Journal of Aggression, Maltreatment \& Trauma, 21, 665-690. https://doi.org/10.1080/10926771.2012.698377

Kira, I., Abou-Median, S., Ashby, J., Lewandowski, L., Mohanesh, J., \& Odenat, L. (2012a). Post-Traumatic Growth Inventory: Psychometric Properties of the Arabic Version in Palestinian Adults. The International Journal of Educational and Psychological Assessment, 11, 120-137.

Kira, I., Abou-Mediene, S., Ashby, J., Odenat, L., Mohanesh, J., \& Alamia, H. (2013a). The Dynamics of Post-Traumatic Growth across Different Trauma Types in a Palestinian Sample. Journal of Loss and Trauma: International Perspectives on Stress \& Coping, 18, 120-139. https://doi.org/10.1080/15325024.2012.679129

Kira, I., Alawneh, A., Aboumediene, S., Lewandowski, L., \& Laddis, A. (2014). Dynamics of Oppression and Coping from Traumatology Perspective: The Example of Palestinian Youth. Peace and Conflict: Journal of Peace Psychology, 20, 385-411. https://doi.org/10.1037/pac0000053

Kira, I., Alawneh, A., N., Aboumediane, S., Mohanesh, J., Ozkan, B., \& Alamia, H. (2011). Identity Salience and Its Dynamics in Palestinians Adolescents. Psychology, 2, 781-791. https://doi.org/10.4236/psych.2011.28120

Kira, I., Ashby, J. S., Lewandowski, L., Alawneh, A. N., Mohanesh, J., \& Odenat, L. (2013b). Advances in Continuous Traumatic Stress Theory: Traumatogenic Dynamics and Consequences of Intergroup Conflict: The Palestinian Adolescents Case. Psychology, 4, 396-409. https://doi.org/10.4236/psych.2013.44057

Kira, I., Fawzi, M., \& Fawzi, M. (2013). The Dynamics of Cumulative Trauma and Trauma Types in Adults Patients with Psychiatric Disorders: Two Cross-Cultural Studies. Traumatology: An International Journal, 19, 179-195. https://doi.org/10.1177/1534765612459892

Kira, I., Lewandowski, L., Templin, T., Ramaswamy, V., Ozkan, B., \& Mohanesh, J. (2010). The Effects of Perceived Discrimination and Backlash on Iraqi Refugees' Physical and Mental Health. Journal of Muslim Mental Health, 5, 59-81. https://doi.org/10.1080/15564901003622110

Kira, I., Shuwiekh, H., \& Bujold-Bugeaud, M. (2015). Gender Discrimination (GD): A Conceptual Trauma-Based Framework for GD and the Development of Gender Discrimination Inventory. Psychology, 6, 2041-2070. https://doi.org/10.4236/psych.2015.616201

Kira, I., Shuwiekh, H., \& Bujold-Bugeaud, M. (2017). Toward Identifying the Etiologies of Gender Differences in Authoritarianism and Mental Health: An Egyptian Study. Peace and Conflict: Journal of Peace Psychology, 23, 183-188. https://doi.org/10.1037/pac0000206

Kira, I., Shuwiekh, H., Al Ibraheem, B., \& Aljakoub, J. (2018b). Appraisals and Emotion Regulation Mediate the Effects of Identity Salience and Cumulative Stressors and Traumas, on PTG and Mental Health: The Case of Syrian's IDPs and Refugees. Self and Identity. 
Kira, I., Shuwiekh, H., Kucharska, J., Abu-Ras, W., \& Bujold-Bugeaud, M. (2017). The Dynamics Underlying the Negative Mental Health Effects of Gender Discrimination in Two Samples: Poland and Egypt. Current Psychology, 1-15. https://doi.org/10.1007/s12144-017-9730-5

Kira, I., Shuwiekh, H., Rice, K., Al Ibraheem, B., \& Aljakoub, J. (2017). A Threatened Identity: The Mental Health Status of Syrian Refugees in Egypt and Its Etiology. Identity, 17, 176-190. https://doi.org/10.1080/15283488.2017.1340163

Kira, I., Templin, T., Lewandowski, L., Ramaswamy, V., Bulent, O., Mohanesh, J., \& Abdulkhaleq, H. (2012b). Collective and Personal Annihilation Anxiety: Measuring Annihilation Anxiety AA. Psychology, 3, 90-99. https://doi.org/10.4236/psych.2012.31015

Krug, G., \& Eberl, A. (2018). What Explains the Negative Effect of Unemployment on Health? An Analysis Accounting for Reverse Causality. Research in Social Stratification and Mobility, 55, 25-39. https://doi.org/10.1016/j.rssm.2018.03.001

Meade, A. W., Johnson, E. C., \& Braddy, P. W. (2008). Power and Sensitivity of Alternative Fit Indices in Tests of Measurement Invariance. Journal of Applied Psychology, 93, 568-592. https://doi.org/10.1037/0021-9010.93.3.568

Pyszczynski, T., Greenberg, J., \& Solomon, S. (1999). A Dual Process Model of Defense against Conscious and Unconscious Death-Related Thoughts: An Extension of Terror Management Theory. Psychological Review, 106, 835-845.

https://doi.org/10.1037/0033-295X.106.4.835

Shaver, P. R., \& Mikulincer, M. E. (2012). Meaning, Mortality, and Choice: The Social Psychology of Existential Concerns. Washington, DC: American Psychological Association. https://doi.org/10.1037/13748-000

Shrira, A. (2015). Transmitting the Sum of All Fears: Iranian Nuclear Threat Salience among Offspring of Holocaust Survivors. Psychological Trauma: Theory, Research, Practice, and Policy, 7, 364-371. https://doi.org/10.1037/tra0000029

Shuwiekh, H., Kira, I. A., \& Ashby, J. S. (2018). What Are the Personality and Trauma Dynamics That Contribute to Posttraumatic Growth? International Journal of Stress Management, 25, 181-194.

van Bruggen, V., Vos, J., Westerhof, G., Bohlmeijer, E., \& Glas, G. (2015). Systematic Review of Existential Anxiety Instruments. Journal of Humanistic Psychology, 55, 173-201. https://doi.org/10.1177/0022167814542048

Weems, C. F., Costa, N. M., Dehon, C., \& Berman, S. L. (2004). Paul Tillich's Theory of Existential Anxiety: A Preliminary Conceptual and Empirical Examination. Anxiety, Stress \& Coping, 17, 383-399. https://doi.org/10.1080/10615800412331318616

Weston, R., \& Gore, P. A. (2006). A Brief Guide to Structural Equation Modeling. The Counseling Psychologist, 34, 719-751. https://doi.org/10.1177/0011000006286345

Wohl, M. J., Branscombe, N. R., \& Reysen, S. (2010). Perceiving Your Group's Future to Be in Jeopardy: Extinction Threat Induces Collective Angst and the Desire to Strengthen the Ingroup. Personality and Social Psychology Bulletin, 36, 898-910. https://doi.org/10.1177/0146167210372505

Yair, G. (2014). Israeli Existential Anxiety: Cultural Trauma and the Constitution of National Character. Social Identities, 20, 346-362. https://doi.org/10.1080/13504630.2014.1002390 


\section{Appendix}

\section{Existential Annihilation Anxiety (EAA) Scale (Long Form)}

Many people have experienced different kinds of events and situations in their lives that challenged their existence personally, or the existence of one of the groups to which they belong. Such challenges may threaten them and made them worry about themselves, their status, their identity or their existence as a person or as a member of the group (for example religious, cultural or ethnic group). These next questions will ask you about some specific situations that may or may not have happened to you in the past (during your life) that may let you feel an existential or annihilation threat. Please rate, if you agree or you disagree with each statement according to the scale indicated after each question:

1. Because of what has happened to me personally or is happening to me now, I sometimes worry that I just lose my sense of self (I worry that I will cease to exist as a person).

$\begin{array}{llll}\text { Strongly Agree } & \text { Agree } & \text { Somewhat Agree } & \text { Disagree } \\ 3 & 2 & 1 & 0\end{array}$

2. The intense violations of me that invaded myself overwhelmed me and made me feel I am losing myself, my independence, fearing of entrapment, or being devoured and losing my ability to function and exist as an autonomous person.

$\begin{array}{llll}\text { Strongly Agree } & \text { Agree } & \text { Somewhat Agree } & \text { Disagree } \\ 3 & 2 & 1 & 0\end{array}$

3. Because of what has happened to me personally or is happening to me now, being fragmented unable to cope, and of losing control, I fear the disintegration of myself or identity.

$\begin{array}{llll}\text { Strongly Agree } & \text { Agree } & \text { Somewhat Agree } & \text { Disagree } \\ 3 & 2 & 1 & 0\end{array}$

4. Sometimes I feel the threat of extermination/annihilation/subjugation (that is, the threat of destruction or "getting rid" of my group) because of discrimination or stereotyping or acts committed against me, my race, religion, culture, or ethnic or cultural group.

$\begin{array}{llll}\text { Strongly Agree } & \text { Agree } & \text { Somewhat Agree } & \text { Disagree } \\ 3 & 2 & 1 & 0\end{array}$

5. One of my groups to which I belong has been threatened in the past, or now by annihilation, extermination, or subjugation which made me worry about persecutions and the existence of them and myself.

$\begin{array}{llll}\text { Strongly Agree } & \text { Agree } & \text { Somewhat Agree } & \text { Disagree } \\ 3 & 2 & 1 & 0\end{array}$

6. Racism, oppression, discrimination, violence and hate against one of my groups to which I belong are humiliating and made me feel that my current or future existence threatened.

Strongly Agree Agree Somewhat Agree Disagree 
3

7

$\begin{array}{llll}\text { Strongly Agree } & \text { Agree } & \text { Somewhat Agree } & \text { Disagree } \\ 3 & 2 & 1 & 0\end{array}$

8. Belonging to an extremely poor family, or being myself relatively poor, made me worry about my existence and ability to survive.

$\begin{array}{llll}\text { Strongly Agree } & \text { Agree } & \text { Somewhat Agree } & \text { Disagree } \\ 3 & 2 & 1 & 0\end{array}$

9. Being disadvantaged because of my particularly unequal lower status, makes me feel dissolving, disappearing or losing my value of existence.

$\begin{array}{llll}\text { Strongly Agree } & \text { Agree } & \text { Somewhat Agree } & \text { Disagree } \\ 3 & 2 & 1 & 0\end{array}$

10. My previous or current loss of job/ business made me feel worthless, nothingness, emptiness, fragmented, self-disintegrated and the loss in my ability to function.

$\begin{array}{llll}\text { Strongly Agree } & \text { Agree } & \text { Somewhat Agree } & \text { Disagree } \\ 3 & 2 & 1 & 0\end{array}$

11. My previous or current failure in school or college made me feel overwhelmed, humiliated, shattered, worthless, nothingness, emptiness, fragmented, self-disintegrated and the loss in my ability to function.

$\begin{array}{llll}\text { Strongly Agree } & \text { Agree } & \text { Somewhat Agree } & \text { Disagree } \\ 3 & 2 & 1 & 0\end{array}$

12. My previous or significant current loss of one of my life assets or achievements, made me overwhelmed, destroyed humiliated, shattered, worthless, nothingness, emptiness, fragmented, self-disintegrated, and caused the loss in my ability to function and fail to exist.

$\begin{array}{llll}\text { Strongly Agree } & \text { Agree } & \text { Somewhat Agree } & \text { Disagree } \\ 3 & 2 & 1 & 0\end{array}$

13. Because of what happened or happening to me, I worry about my death (physical elimination).

$\begin{array}{llll}\text { Strongly Agree } & \text { Agree } & \text { Somewhat Agree } & \text { Disagree } \\ 3 & 2 & 1 & 0\end{array}$

14. Because of what happened or happening to me, I think a lot about my death.

$\begin{array}{llll}\text { Strongly Agree } & \text { Agree } & \text { Somewhat Agree } & \text { Disagree } \\ 3 & 2 & 1 & 0\end{array}$

15. Because of what happened or happening to me, I am very afraid of death.

$\begin{array}{llll}\text { Strongly Agree } & \text { Agree } & \text { Somewhat Agree } & \text { Disagree } \\ 3 & 2 & 1 & 0 \\ \text { Scoring Keys } & & & \end{array}$

Items 1-3: Psychic (personal identity) Existential Annihilation Anxiety (EAA) Subscale (3 items) 
Items 4-7: Collective identity (EAA) Subscale (4 items)

Items 8-12: Role and status identity (EAA) Subscale (5 items)

Items 13-15: Physical (EAA) Subscale (3 items)

EAA total scale: 1-15 